NBER WORKING PAPER SERIES

POLITICS AND TRADE POLICY

Elhanan Helpman

Working Paper 5309

\author{
NATIONAL BUREAU OF ECONOMIC RESEARCH \\ 1050 Massachusetts Avenue \\ Cambridge, MA 02138 \\ October 1995
}

I am grateful to the NSF for financial support and to Gene Grossman and Alan Winters for comments. This paper is part of NBER's research programs in International Finance and Macroeconomics, and International Trade and Investment. Any opinions expressed are those of the author and not those of the National Bureau of Economic Research.

(C) 1995 by Elhanan Helpman. All rights reserved. Short sections of text, not to exceed two paragraphs, may be quoted without explicit permission provided that full credit, including $\odot$ notice, is given to the source. 


\title{
POLITICS AND TRADE POLICY
}

\begin{abstract}
First I describe a number of political economy approaches that have been developed to explain trade policies. All approaches are presented in a unified framework that helps to see the key differences among them. These comparisons revolve around tariff formulas that are predicted by political equilibria. A typical formula explains cross-sectoral variations in rates of protection as well as differences in average rates of protection across countries. Second, I review a set of results that emerge from a new approach to the interaction of international economic relations with domestic politics. Importantly, there are two-way interactions in such systems. They link the formation of trade policies in the international arena with the activities of domestic special interest groups. The use of a framework of this sort is essential for a proper analysis of a host of important problems, such as negotiations about tariff levels or the formation of free trade areas. Recent studies have developed suitable tools for this purpose.
\end{abstract}

Elhanan Helpman

The Eitan Berglas School of Economics

Tel Aviv University

Tel Aviv 69978

ISRAEL and NBER 


\section{Introduction}

Economists have devoted much effort to the study of efficiency properties of trade policies. These efforts have produced a coherent body of literature that describes how trade policy instruments - such as tariffs, export subsidies, quotas or voluntary export restraints - affect economies that trade with each other. And they produced empirical models that have been extensively used to evaluate the efficiency losses from trade policies on the one hand and prospective gains from trade reforms on the other. Recent examples include quantitative studies of the single market program in Europe (e.g. Flam (1992)) and of NAFTA (e.g. Garber (1994)).

At the same time another strand of the literature has examined possible explanations for prevailing trade policies. Here efficiency considerations have not played center stage. Many policies - such as quotas and voluntary export restraints - impose large burdens on society. Therefore researches looked for objectives of the policy makers other than overall efficiency in order to explain them. This literature emphasizes distributional considerations. It views trade policy as a device for income transfers to preferred groups in society. And it explains the desire of a policy maker to engage in this sort of costly transfer by means of political arguments in her objective function (see Hillman (1989) for a review).

Political economy explanations of trade policies are important, because they help to understand the structure of protection as well as major public policy debates. It would be impossible, in fact, to understand such debates without paying close attention to political considerations. Recent examples include the debate about NAFTA in the USA, in which special interests - such as the sugar industry - were able to effectively voice their concerns in Congress. Or the debate about the Uruguay round in France, that brought farmers out into the streets. Quite often countries design their trade policies in a way that yields to pressure from special interest groups, and trade negotiations at the international arena respond similarly.

As important as the political economy of trade policy seems to be, however, there 
exists no coherent theory to explain it. Models that underline some features of the policy formation process have been designed by economists and political scientists. But they do not add up as yet to a coherent theory. One reason for this state of affairs is that there exists no agreed upon theory of domestic politics. This reflects partly the fact that there are many channels through which residents convey their desire to policy makers, and these ways differ across issues and across concerned groups in society. Moreover, political institutions vary across countries and they affect the ways in which influence works out through the system. As a result there are potentially many modes of interaction that require close scrutiny. Special interest politics are prevalent, however, and economists need to understand these processes in order to better predict policy outcomes and to better design feasible policy options.

My purpose is to describe in this paper a number of political economy approaches that have been developed to explain trade policies. I present these approaches in section 2, using a unified framework that helps to see the key differences among them. These comparisons revolve around tariff formulas that are predicted by the political equilibria. A typical formula explains cross-sectoral variations in rates of protection as well as differences in average rates of protection across countries. Section 3 then reviews a set of results that emerge from a new approach to the interaction of international economic relations with domestic politics. Importantly, there are twoway interactions in such systems, as pointed out by Putnam (1988). They link the formation of trade policies in the international arena with the activities of domestic special interest groups. The use of a framework of this sort is essential for a proper analysis of a host of important problems, such as negotiations about tariff levels or the formation of free trade areas. Recent studies have developed suitable tools for this purpose, as I will argue in section 3 . 


\section{Political Economy Approaches}

I briefly describe in this section some of the leading political economy approaches to the formation of trade policies.

\subsection{Direct Democracy}

Wolfgang Mayer (1984) proposed to view trade policy as the outcome of majority voting over tariff levels. There are, of course, very few countries in which direct democracy is applied to a broad range of issue, Switzerland being the prime example. Nevertheless, there exists a view that in representative democracies policy outcomes are reasonably close to what is supported by a majority of the voters. In such cases the simple analysis of majority voting serves as a good approximation. There remains, of course, the difficulties involved in voting over multi-dimensional issues, that have not yet been resolved (see Shepsle (1990)). And these difficulties apply to trade policies, which are often multi-dimensional in character. Witness, for example, the various rounds of trade liberalization under the auspices of the GATT (the Uruguay round being the last one), in which the removal of many tariffs and other trade barriers were negotiated simultaneously. Nevertheless, we may be able to learn something useful from the direct democracy approach.

The essence of Mayer's approach is quite simple. Suppose that a country has to decide the level of a particular tariff rate. We shall denote by $\tau_{i}$ one plus the tariff rate on product $i .{ }^{1}$ Then we can derive a reduced-form indirect utility function for each voter $j, \hat{v}_{i}\left(\tau_{i}, \gamma^{j}\right)$, where $\gamma^{j}$ is a vector of the voter's characteristics. These characteristics may include his endowment (such as his skills, his ownership of shares in companies) or parameters describing his preference for consumption. Naturally,

\footnotetext{
${ }^{1}$ When $\tau_{i}$ is larger than one and the good is imported, we have a proper tariff. Alternatively, when $\tau_{i}$ is smaller than one and the good is imported, we have a subsidy to imports. If the good is exported and $\tau_{i}$ is larger than one we have an export subsidy and if $\tau_{i}$ is smaller than one and the good is exported we have an export tax.
} 
the shape of $\hat{v}_{i}(\cdot)$ depends on various details of the economy's structure. If individual $j$ was asked to choose the tariff level that he prefers most, he would choose $\tau_{i}$ that maximizes $\hat{v}_{i}\left(\tau_{i}, \gamma^{j}\right){ }^{2}$ Let $\hat{\tau}_{i}\left(\gamma^{j}\right)$ describe the solution to this problem as a function of the individual's characteristics. The assumption that $\hat{\tau}_{i}(\cdot)$ is a function means that individual preferences over tariff rates are single-peaked. Under these circumstances voting over pairs of alternative tariff rates leads to the adoption of $\tau_{i}^{m}$, which is most preferred by the median voter. Namely, it is the tariff rate that has the property that the number of voters that prefer a higher rate equals the number of voters that prefer a lower rate. As a result no other tariff obtains more votes in a competition with $\tau_{i}^{m}$.

Mayer studied properties of the equilibrium rate of protection $\tau_{i}^{m}$ in a HeckscherOhlin type two-sector two-factor economy, in which all individuals have the same homothetic preferences, every sector produces a homogenous product under constant returns to scale, and people differ in their relative endowment of the two factors. Taking labor and capital to be the two factors, $\gamma^{j}$ represents the capital-labor ratio owned by individual $j$. Then, assuming that tariff revenue is redistributed to the public in proportion to income, he was able to derive the most preferred tariff rate of the median voter and to study its characteristics.

As an example of tariffs determined by direct voting, I now develop a model that will also be used for future purposes. Consider an economy with a continuum of individuals. Each individual has the utility function

$$
u(c)=c_{0}+\sum_{i=1}^{n} u_{i}\left(c_{i}\right)
$$

where $c_{i}$ is consumption of product $i$ and $u_{i}(\cdot)$ is an increasing concave function. Population size equals one.

Let there be labor and a sector-specific input in each sector $i$. Aggregate labor supply is normalized to equal one. Individual $j$ owns the fraction $\gamma_{L}^{j}$ of labor. ${ }^{3}$ The

\footnotetext{
${ }^{2}$ Depending on context, it may be necessary to limit the choice of $\tau_{i}$ to some feasible set. Obviously, it has to be non-negative. But some upper limit may also exist as a result of political constraints or international agreements.

${ }^{3}$ The discussion in the text assumes that the distribution of the ownership of labor and sector
} 
numeraire good, indexed 0 , is produced only with labor, using one unit of labor per unit output. Each one of the remaining goods is produced with labor and the sector specific input. We shall measure all prices in terms of the numeraire. Then the wage rate equals one and the reward to the sector specific input in sector $i, \Pi_{i}\left(p_{i}\right)$, is an increasing function of the producer price of product $i, p_{i}$. Now normalize all foreign prices to equal one. Then $p_{i}=\tau_{i}$. Next let $\gamma_{i}^{j}$ represent the fraction of the sector- $i$ specific input owned by individual $j .{ }^{4}$ Finally, suppose that the government redistributes tariff revenue in a lump-sum fashion and equally to every individual. It then follows that the reduced form indirect utility function is given by

$$
\hat{v}\left(\tau, \gamma^{j}\right)=\gamma_{L}^{j}+\sum_{i=1}^{n}\left(\tau_{i}-1\right) M_{i}\left(\tau_{i}\right)+\sum_{i=1}^{n} \gamma_{i}^{j} \Pi_{i}\left(\tau_{i}\right)+\sum_{i=1}^{n} S_{i}\left(\tau_{i}\right)
$$

where $M_{i}\left(\tau_{i}\right)$ represents aggregate imports of product $i .^{5,6}$ The first term on the right hand side represents labor income. The second term represents income from the government's transfer and the third term represents income from the ownership of sector specific inputs. The last term represents consumer surplus.

It is evident from (2) that individual $j$ 's preference for the tariff rate in sector $i$ depends only on his fraction of ownership of the sector specific input in that sector. This preference function can be represented by $\hat{v}_{i}\left(\tau_{i}, \gamma_{i}^{j}\right)=\left(\tau_{i}-1\right) M_{i}\left(\tau_{i}\right)+\gamma_{i}^{j} \Pi_{i}\left(\tau_{i}\right)+$ $S_{i}\left(\tau_{i}\right) .{ }^{7}$ As a result we have $\partial \hat{v}_{i}\left(\tau_{i}, \gamma_{i}^{j}\right) / \partial \tau_{i}=\left(\tau_{i}-1\right) M_{i}^{\prime}\left(\tau_{i}\right)+\left(\gamma_{i}^{j}-1\right) X_{i}\left(\tau_{i}\right)$, where $X_{i}=\Pi_{i}^{\prime}$ represents the output level in sector $i$. Since imports decline with the tariff, it follows that individuals with above average ownership of the sector specific specific inputs is atomless; i.e., it is thinly dispersed in the population. As a result, $\gamma_{L}^{j}$ is treated as the measure of labor owned by individual $j$, implying $\int_{j} \gamma_{L}^{j} d j=1$.

${ }^{4}$ I.e., $\int_{j} \gamma_{i}^{j} d j=1$ for every $i=1,2, \ldots, n$.

${ }^{5}$ When there are trade taxes only, the consumer price equals the producer price.

${ }^{6} \mathrm{As}$ is well known, the utility function (1) has an associated standard indirect utility function $v(p, E)=E+\sum_{i=1}^{n} S_{i}\left(p_{i}\right)$, where $E$ represents total spending and $S_{i}\left(p_{i}\right)=u_{i}\left[d_{i}\left(p_{i}\right)\right]-p_{i} d_{i}\left(p_{i}\right)$ is the consumer surplus from product $i$, where $d_{i}\left(p_{i}\right)$ is the demand function for product $i$. Imports of product $i$ are given by $M_{i}\left(\tau_{i}\right)=-\left[S_{i}^{\prime}\left(\tau_{i}\right)+\Pi_{i}^{\prime}\left(\tau_{i}\right)\right]$.

${ }^{7}$ Namely, the reduced form indirect utility function (2) is given by $\hat{v}\left(\tau, \gamma^{j}\right)=\gamma_{L}^{j}+\sum_{i=1}^{n} \hat{v}_{i}\left(\tau_{i}, \gamma_{i}^{j}\right)$. 
input vote for a tariff while individuals with below average ownership vote for an import subsidy. ${ }^{8}$ And an individual's most preferred tariff rate is higher the larger his ownership share of the sector-specific input. It follows that voting on the tariff level in sector $i$ leads to a tariff rate that is most preferred by the individual with the median value of $\gamma_{i}^{j}$. The larger this median value $\gamma_{i}^{m}$, the higher the resulting tariff rate. When the median voter's most preferred tariff rate is not on the boundary of the feasible set, it can be calculated from the condition $\partial \hat{v}_{i}\left(\tau_{i}, \gamma_{i}^{m}\right) / \partial \tau_{i}=0$, which yields the following formula for the equilibrium tariff: ${ }^{9}$

$$
\tau_{i}-1=\left(\gamma_{i}^{m}-1\right) \frac{X_{i}}{\left(-M_{i}^{\prime}\right)} .
$$

The tariff rate is higher when the median voter's share of ownership of the sector specific input is higher, and it also is higher the larger the sector in terms of output and the smaller the slope of the import demand function. Larger output levels imply higher stakes for the industry, which makes it more profitable to have a high tariff (as long as $\gamma_{i}^{m}$ is above average). While the less elastic the import demand function, the lower the excess burden of a tariff. Part of this excess burden is born by the median voter. Therefore he prefers a higher tariff rate the lower this marginal cost. This is, of course, a standard consideration in Ramsey pricing.

One last point should be noted concerning equilibrium tariff rates in a direct democracy. My discussion assumed that the ownership of the sector specific inputs is thinly dispersed in the population. Occasionally (or perhaps even often) this is not the case. So consider the other extreme case, in which, say, the ownership of the sector-specific input in sector $k$ is highly concentrated, up to the point that it is owned by a negligible fraction of the population. Under these circumstances a member of

\footnotetext{
${ }^{8}$ I use the term "tariff" to mean $\tau_{i}>1$ independently of whether the good is imported or exported. Also observe that under our normalization of the population size; i.e., that the population equals one, the average ownership share of a sector specific input equals one.

${ }^{9}$ Output and the slope of the import demand function depend on the tariff rate, but these arguments have been suppressed in the following formula for convenience.
} 
this minority group, who owns a finite amount of the sector-specific input, wants the tariff rate to be as high as possible. On the other hand, an individual who has no ownership of this input whatsoever wants an import subsidy. Since the latter type of people represent almost one hundred percent of the voters, the median voter most prefers to subsidize imports. More generally, it is clear from this example that under majority voting we should not observe tariffs but rather import subsidies in sectors with a highly concentrated ownership. If anything, the opposite seems to be true. As argued by Olsen (1965), however, in sectors with a highly concentrated ownership it is relatively easy to overcome the free-rider problem and to form pressure groups whose purpose it is to protect sector specific incomes. Therefore we need to consider the role of such organizations in the shaping of trade policies. to which we will turn at a later stage.

\subsection{Political Support Function}

An alternative approach was proposed by Hillman (1982). Borrowing from the theory of economic regulation, as developed by Stigler (1971) and Peltzman (1976), he suggested that we could view the choice of a tariff rate as the solution to an optimizing problem in which the government trades off political support from industry interests against the dissatisfaction of consumers. Industry interests provide more support the higher the industry's profits, while the government gains more support from consumers the lower the consumer price. In the event, by raising domestic prices higher tariffs bring about more support from industry interests - whose profits rise and less support from consumers - whose real income declines. And the government chooses a tariff level that maximizes aggregate support.

Hillman postulated a reduced-form aggregate support function for a tariff in sector $i, P_{i}\left[\Pi_{i}\left(p_{i}\right)-\Pi_{i}\left(p_{i}^{*}\right), p_{i}-p_{i}^{*}\right]$, in which the first argument represents the gain in profits from a trade policy that raises the domestic price from the free-trade price $p_{i}^{*}$ to $p_{i}$, while the second term represents the loss in consumer welfare that results from the 
same price increase. Political support rises in the first argument, and it declines in the second argument for $p_{i}^{*}<p_{i}$. Hillman used this approach to study the trade policy response to a declining foreign price. In particular, he showed that under mild assumptions a decline in the foreign price leads to higher domestic protection, but the resulting tariff increase does not fully compensate for the fall in the foreign price. As a result, the decline in the foreign price leads to a decline in the domestic price as well, but to a lesser degree.

I will now reformulate the political-support-function approach in order to derive a formula for equilibrium tariff rates that is comparable to (3). For this purpose suppose that the economic structure is the same as in section 2.1. In this event we can use (2) to calculate aggregate welfare, by integrating the individual welfare functions over the entire population. The result is

$$
W(\tau)=1+\sum_{i=1}^{n}\left(\tau_{i}-1\right) M_{i}\left(\tau_{i}\right)+\sum_{i=1}^{n} \Pi_{i}\left(\tau_{i}\right)+\sum_{i=1}^{n} S_{i}\left(\tau_{i}\right)
$$

Next, suppose that the government's political support for a policy is an increasing function of the income gains of sector specific inputs and of the aggregate welfare gain. For simplicity assume that this function is linear; ${ }^{10}$ i.e.,

$$
\hat{P}(\tau)=\sum_{i=1}^{n} \frac{1}{a_{p i}}\left[\Pi_{i}\left(\tau_{i}\right)-\Pi_{i}(1)\right]+[W(\tau)-W(1,1, \ldots, 1)] .
$$

The parameter $a_{p i}$ represents the marginal rate of substitution in the government's political support function between aggregate welfare and profits of special interests in sector $i$. These parameters are allowed to vary across sectors. The larger $a_{p i}$, the more willing is the government to give up profits of sector- $i$ interests in exchange for aggregate welfare. The government chooses rates of protection to maximize its political support, as measure by $\hat{P}(\tau)$. Using (4) and (5), an interior solution to this

\footnotetext{
${ }^{10}$ The assumption of linearity is inconsequential for our purpose. With a non-linear political support function the formula of the tariff rate has a marginal rate of substitution $a_{p i}$ that depends on the levels of income of sector specific inputs and on aggregate welfare.
} 
maximization problem implies the following tariff rates: ${ }^{11}$

$$
\tau_{i}-1=\frac{1}{a_{p i}} \frac{X_{i}}{\left(-M_{i}^{\prime}\right)} .
$$

Comparing this formula with (3), we see that they are the same, except for the fact that the parameter $1 / a_{p i}$ replaces $\left(\gamma_{i}^{m}-1\right)$. Namely, in both cases the tariff is higher the larger the sector's output level and the flatter the import demand function. Importantly, however, while the political support function approach implies that each sector in which special interests count (i.e., in which $a_{p i}$ is finite) will be protected and no sector will be afforded negative protection, direct voting over tariff rates brings about positive protection in sectors with median ownership of sector-specific inputs larger than the average, but negative protection in sectors in which median ownership of sector-specific inputs falls short of the average. It follows that in a direct democracy the distribution of ownership has an important effect on the structure of protection, while in a representative democracy - in which the government evaluates a political-support function in its design of trade policy - the political support function's marginal rates of substitution between the well being of consumers and sectoral interests importantly affect the structure of protection. Evidently, building on the political-support-function approach, a better understanding of the forces that shape the structure of protection requires some insights on what determines the marginal rates of substitution between aggregate welfare and special interest profits. Unfortunately, the theory is not particularly helpful on this critical point.

\footnotetext{
11 Observe that by substituting (4) into (5) we obtain an objective function in which every dollar of real income obtains a weight of 1 , except for income from a sector specific input that obtains a weight of $1+1 / a_{p i}$. These differential weights on different sources of real income drive the results. Long and Vousden (1991) have proposed a somewhat different approach to the formulation of political support functions, in which the weights vary across individuals rather than across sources of income.
} 


\subsection{Tariff Formation Function}

The political support function summarizes a trade off between the support that a government obtains from special interests on the one hand, and the support of consumers on the other. Under this approach, a government designs its trade policy so as to balance the conflict between these opposing groups in a way that serves it best. Considerations of this sort are, of course, quite common in representative democracies, and even in totalitarian regimes rulers tend to listen to the concerns of the general public. But competition for preferential treatment very often takes on an active form, rather than the passive form envisioned in the political support function approach. Lobbying for the protection of real incomes is prevalent, and many interest groups participate in this process.

To deal with the active seeking of protection of real incomes, Findlay and Wellisz (1982) proposed the use of tariff-formation functions. A function of this sort describes the level of protection afforded to an industry as depending on the amount of resources devoted to lobbying by a group of supporters of protection on the one hand, and by the lobbying efforts of opposers of protection on the other. According to this view, the level of protection reflects the outcome of a contest between interest groups on the opposing sides of the issue. ${ }^{12}$ More precisely, let $T_{i}\left(C_{i}^{S}, C_{i}^{O}\right)$ describe the tariff formation function in sector $i$, where $C_{i}^{S}$ represents the lobbying expenditure of the pro-protectionist interest group and $C_{i}^{O}$ represents the lobbying expenditure of the anti protectionist interest group. The resulting rate of protection is higher the larger the expenditure of the former group and the lower the expenditure of the latter. In the political equilibrium $\tau_{i}=T_{i}\left(C_{i}^{S}, C_{i}^{O}\right)$.

In order to derive the equilibrium level of protection, we need to describe the incentives of the various interest groups. So suppose that the benefits of the pro-

\footnotetext{
${ }^{12}$ Feenstra and Bhagwati (1982) take a similar approach, except that they view the government as the defender of the public interest. As a result, the lobbying costs of the pro-protectionist coalition rise with the price distortion. We will come back to this point at a later stage.
} 
protectionist lobby are given by the increasing function $W_{i}^{S}\left(\tau_{i}\right)$ while the benefits of the opposition are given by the declining function $W_{i}^{O}\left(\tau_{i}\right)$, both measured in terms of numeraire income. Then the lobbying expenditure levels are determined as the Nash equilibrium of a non-cooperative game in which each interest group chooses its lobbying expenditure so as to maximize net benefits, which are $W_{i}^{S}\left[T_{i}\left(C_{i}^{S}, C_{i}^{O}\right)\right]-C_{i}^{S}$ for the pro-protectionist lobby and $W_{i}^{O}\left[T_{i}\left(C_{i}^{S}, C_{i}^{O}\right)\right]-C_{i}^{O}$ for its rival. Findlay and Wellisz developed a two-sector specific-factor model, in which the owners of the specific factor in the import-competing industry lobby for import protection while the owners of the specific factor in the exporting industry oppose protection. As is well known, in an economy of this type the former group gains from protection while the latter group loses (see Jones (1971)), therefore they naturally take the opposite side of the protection issue. In this framework Findlay and Wellisz have investigated the determinants of the equilibrium rate of protection. Given that the results depend on the shape of the tariff formation function, however, and the fact that their theory has little to say about this shape, they were unable to derive sharp predictions.

In order to relate this approach to my previous discussion, let us consider a somewhat different variant of the tariff formation model. Suppose that the economy is the same as in section 2.1. Also suppose that the owners of the sector- $i$ specific factor form an interest group that lobbies for protection. The purpose of the lobby is to maximize the individuals' joint welfare. Joint welfare maximization is suitable whenever the interest group can resolve its internal conflicts, such as ensuring the participation of all factor owners and the distribution of the burden of the lobbying expenses among them. If these owners constitute a fraction $\alpha_{i}$ of the population, then the joint welfare that they derive from sector $i$ can be represented by (see (2)): ${ }^{13}$

$$
W_{i}^{S}\left(\tau_{i}\right)=\Pi_{i}\left(\tau_{i}\right)+\alpha_{i}\left[\left(\tau_{i}-1\right) M_{i}\left(\tau_{i}\right)+S_{i}\left(\tau_{i}\right)\right]
$$

The first term on the right-hand side represents income of the sector-specific input while the second term describes the share of the lobby in the tariff rebate and in

\footnotetext{
${ }^{13}$ I exclude the constant term for labor income from this formula.
} 
consumer surplus. So this describes the benefit function of the protectionist lobby. Marginal benefits of protection equal $W_{i}^{S \prime}=\left(1-\alpha_{i}\right) X_{i}+\alpha_{i}\left(\tau_{i}-1\right) M_{i}^{\prime}$, which are positive for values of $\tau_{i}$ that are not too large.

Next suppose that there exists a lobby that opposes protection, which consists of all the other individuals in the economy. ${ }^{14}$ The joint welfare that this group derives from a given tariff level equals

$$
W_{i}^{O}\left(\tau_{i}\right)=\left(1-\alpha_{i}\right)\left[\left(\tau_{i}-1\right) M_{i}\left(\tau_{i}\right)+S_{i}\left(\tau_{i}\right)\right]
$$

Namely, they obtain a fraction $1-\alpha_{i}$ of the tariff rebate and the same fraction of consumer surplus. To this group the marginal benefit of protection equals $W_{i}^{O \prime}=$ $\left(1-\alpha_{i}\right)\left[-X_{i}+\left(\tau_{i}-1\right) M_{i}^{\prime}\right]$, which is negative for positive rates of protection (i.e., for $\left.\tau_{i}>1\right)$.

Finally, consider an interior equilibrium to the non-cooperative game between the interest groups. The first order conditions for the choice of lobbying expenditures that maximizes net benefits are given by $\left[\left(1-\alpha_{i}\right) X_{i}+\alpha_{i}\left(\tau_{i}-1\right) M_{i}^{\prime}\right] T_{i S}=1$ for the protectionist lobby and by $\left(1-\alpha_{i}\right)\left[-X_{i}+\left(\tau_{i}-1\right) M_{i}^{\prime}\right] T_{i O}=1$ for its rival. $T_{i S}$ and $T_{i O}$ represent partial derivatives of the tariff formation function with respect to the spending levels of the pro-protectionist lobby and the anti protectionist lobby, respectively. In the first condition, the left-hand side represents the marginal benefit of an additional dollar spent to promote protection, which consists of the product of the marginal benefit of protection and the marginal gain in protection from a dollar of spending. The right-hand side represents the marginal cost. A pro-protectionist lobby chooses its spending level so as to balance costs and benefits at the margin. A similar interpretation can be given to the second condition, which applies to the interest group that opposes protection. Together these conditions yield

$$
\tau_{i}-1=\frac{\left(1-\alpha_{i}\right)\left(b_{i}-1\right)}{\alpha_{i} b_{i}+\left(1-\alpha_{i}\right)} \frac{X_{i}}{\left(-M_{i}^{\prime}\right)},
$$

\footnotetext{
${ }^{14}$ It is, of course, not realistic to assume that the anti-protectionist lobby consists of all other individuals in the economy. But it simplifies the exposition.
} 
where $b_{i}=-T_{i S} / T_{i O}>0$ represents the marginal rate of substitution between the spending levels on lobbying in the tariff-formation function. ${ }^{15}$ When $b_{i}>1$, a marginal dollar of spending on lobbying by the pro-protectionist interest group raises the tariff by more than it declines as a result of an extra dollar of spending on lobbying by the anti protectionist interest group. We see from this equation that the sector is protected if and only if $b_{i}>1$. And if a marginal lobbying dollar of one interest group is as effective as a marginal lobbying dollar of the other interest group, then there is free trade. Importantly, whenever the sector is protected, the rate of protection is higher the more effective is a lobbying dollar of the pro-protectionist interest group relative to a lobbying dollar of the anti protectionist interest group, and the smaller the fraction of people that belong to the former group. The last result implies that the more highly concentrated is the ownership of a sector-specific factor, the higher will be the rate of protection afforded to this sector. This result - which is just the opposite from the prediction of the direct voting model - stems from the fact that the fewer the owners of the sector specific input, the less account does the lobby take of the excess burden produced by protection. In the extreme case, when the entire population has a stake in the sector, free trade prevails, because the lobby internalizes all welfare considerations. Finally, as in the previously discussed cases, the rate of protection is higher the larger the output level and the flatter the import demand function.

Formula (7) results partly form the assumption that the opposition to the proprotectionist lobby consists of all the other individuals in the economy. This is obviously not the typical case. The important point is, however, that the welfare of at least some fraction of the general public counts in the design of a trade policy. Those members of society may be represented by an organized group or by the government itself. In the latter case the government's motivation may be the desire to do good or

\footnotetext{
${ }^{15}$ If only a fraction $\alpha_{i}^{O}<1-\alpha_{i}$ of individuals belong to the anti-protectionist lobby, then the first term on the right-hand side of (7) should be replaced with $\left[\left(1-\alpha_{i}\right)\left(b_{i}-1\right)+1-\alpha_{i}-\alpha_{i}^{O}\right] /\left(\alpha_{i} b_{i}+\alpha_{i}^{O}\right)$.
} 
just cool political calculus. Indeed, Feenstra and Bhagwati (1982) have used a tariff formation function with a government that cares about welfare of the general public. Under these circumstances the desire to minimize excess burden plays an important role.

\subsection{Electoral Competition}

Unlike most other approaches to the politics of trade policy, Magee, Brock and Young (1989) advocate an emphasis on electoral competition. ${ }^{16}$ According to this view interest groups give contributions to political parties and candidates in order to improve their chances for being elected. This contrasts with the tariff-formation-function approach in which contributions influence policy choices. For this reason M-B-Y construct a model in which two parties compete in an election. Each one commits to a policy before the choice of contributions by special interests. As a result, the choice of contributions does not affect policy choices and their only role is to improve the likelihood of one or the other party being elected. Anticipating the electoral motive in campaign giving, however, the parties - which are interested in maximizing their electoral prospects at the polls - choose policies that correctly anticipate future campaign contributions.

Somewhat more formally, suppose that there are two political parties and two lobbies. Each lobby is aligned with one party. In M-B-Y there is a pro-capital party with which the lobby of capital owners is aligned and a pro-labor party with which labor is aligned. Other alignments are of course possible, depending on context. For present purposes let us be agnostic about the precise interpretation of these allegiances, and let us have party $A$ and party $B$, and lobby 1 and lobby 2 . Lobby 1 is aligned with party A while lobby 2 is aligned with party B. Party A gets elected with probability $q\left(\sum_{i=1}^{2} C_{i}^{A}, \sum_{i=1}^{2} C_{i}^{B}, \tau^{A}, \tau^{B}\right)$, where $C_{i}^{K}$ stands for the contribution of lobby $i$ to the

\footnotetext{
${ }^{16}$ Electoral competition is implicit in both the political-support-function and the tariff-formationfunction approaches, while in the Magee, Brock and Young approach it plays center stage.
} 
political campaign of party $K$ and $\tau^{K}$ is the trade policy of party $K$. This probability is higher the more contributions party $\mathrm{A}$ amasses, the less contributions party $\mathrm{B}$ amasses, the less distortive is the trade policy of party $A$ and the more distortive is the trade policy of party B. -

In the second stage of the game, after the parties have committed to their trade policies, the lobbies decide on campaign contributions. Let $W_{i}(\tau)$ be the benefit function of lobby $i$ when the trade policy is $\tau$. Then this lobby expects the benefit level $W_{i}\left(\tau^{A}\right)$ with probability $q(\cdot)$ and the benefit $W_{i}\left(\tau^{B}\right)$ with probability $1-q(\cdot)$. Lobbies choose their contributions non-cooperatively. Therefore, contributions are a Nash equilibrium of the game in which each lobby maximizes its expected net benefit. Namely, the best response of lobby $i$ to the contribution levels of the other lobby is given by the solution to the following problem:

$$
\begin{gathered}
\max _{C_{i}^{A} \geq 0, C_{i}^{B} \geq 0} q\left(\sum_{i=1}^{2} C_{i}^{A}, \sum_{i=1}^{2} C_{i}^{B}, \tau^{A}, \tau^{B}\right) W_{i}\left(\tau^{A}\right) \\
+\left[1-q\left(\sum_{i=1}^{2} C_{i}^{A}, \sum_{i=1}^{2} C_{i}^{B}, \tau^{A}, \tau^{B}\right)\right] W_{i}\left(\tau^{B}\right)-\sum_{K=A, B} C_{i}^{K} .
\end{gathered}
$$

In the resulting Nash equilibrium the contribution levels are functions of the tax policies. Substituting these functions into $q(\cdot)$ yields a reduced form probability function that depends only on the trade policies, $\tilde{q}\left(\tau^{A}, \tau^{B}\right)$. The function $\tilde{q}(\cdot)$ anticipates the contribution game that will be played by the lobbies for each policy choice by the parties. In the first stage the parties play a non-cooperative game. Each one chooses its policy so as to maximize its probability of winning the election. Therefore party $A$ chooses $\tau^{A}$ so as to maximize $\tilde{q}\left(\tau^{A}, \tau^{B}\right)$ while party $\mathrm{B}$ chooses $\tau^{B}$ so as to maximize $1-\tilde{q}\left(\tau^{A}, \tau^{B}\right)$. The Nash equilibrium of this game identifies the equilibrium levels of the rates of protection.

Mayer and Li (1994) have re-examined the M-B-Y analysis, using probabilistic voting theory as the micro foundations. Probabilistic voting allows for preferences of voters that depend on economic policies as well as on other attributes of political parties, such as their positions on social issues or political ideology. Preferences over 
non-economic issues are diverse and parties know only their distribution in the voting population (see Coughlin (1992)). Mayer and Li also assume that voters are not sure about the economic policy stance of the parties, and that each party can use campaign contributions in order to clarify their position. Each party chooses its policy so as to maximize the probability of being elected.

Their analysis supports some of M-B-Y's conclusions, but not all. For example. it supports the result that a lobby will contribute to at most one political party; i.e., lobbies specialize in campaign giving. Unfortunately, this result does not fare well on empirical grounds; it is quite common in parliamentary systems for lobbies to contribute to the two major political parties (e.g., Israel). On the other hand. Mayer and $\mathrm{Li}$ find that both lobbies may end up contributing to the same political party, while M-B-Y assumed that each lobby is aligned with one party only. My conclusion from the Mayer- $\mathrm{Li}$ analysis is that it is indeed important to develop more detailed models in order to deal satisfactorily with the role of the electoral motive for campaign contributions in the political economy of trade policies. More about it in the next section.

\subsection{Influence-Driven Contributions}

Political contributions that influence election outcomes are a desirable feature of trade policy models. They seem to emphasize, however, a motive for contributions that is at most secondary. To be sure, from the point of view of politicians and their political parties the total amount of contributions serve an important role in enhancing their chances of being elected or re-elected. But this does not mean that the individual contributors view the improved chance of a candidate as a major consideration in their giving. For one thing, there typically exist many contributors with the contribution of each one being small relative to the total. This is particularly true in countries with legal limits on contributions, but not only in countries of this type. As a result, each contribution has a marginal effect on the election outcome. Under these circumstances 
it is more likely that contributions are designed to influence the choice of policy than to influence election outcomes. Namely, having a choice between an emphasis on the electoral motive for contributions (as in M-B-Y) and an influence motive, the latter seems to be more attractive on theoretical grounds. This point is made explicit in the detailed model of electoral competition and special interest politics by Grossman and Helpman (1994b), in which they show that with a large number of organized interest groups the electoral motive for campaign contributions is negligible. ${ }^{17}$

At the same time the empirical literature also supports the view that the influence motive is more prominent. For example, Magelby and Nelson (1990) report that: (a) Political action committees (PACs) in the US gave mor than three quarters of their total contributions in the 1988 Congressional campaign to incumbent candidates. (b) Not counting elections for open seats, incumbents received over 6 times as much as challengers. (c) Over $60 \%$ of the campaign contributions by PACs occurred in the early part of the election cycle, often before a challenger had even been identified. (d) PACs switch their contributions to the winner even if they supported the loser to begin with. In addition, in parliamentary democracies, interest groups often contribute simultaneously to more than one major political party.

Relying on these considerations, Grossman and Helpman (1994a) have developed a theory that puts the influence motive at the heart of campaign contributions. According to this approach, interest groups move first, offering politicians campaign contributions that depend on their policy stance. Special interests seek to maximize the well being of their members. Then the politicians choose policy stances, knowing how their contributions depend on the selected polices. Politicians seek to maximize a political objective function that depends on contributions and on the well being of the general public. ${ }^{18}$

\footnotetext{
${ }^{17}$ The influence motive generates benefits to the lobbies that are of the same order of magnitude as their contributions. This feature makes it desirable to exploit this motive for contributions even when there exists a large number of interest groups.

${ }^{18}$ The political-support-function approach can be interpreted as a reduced form of the influence-
} 
A political objective function that depends on contributions and the well being of voters is consistent with electoral competition. Grossman and Helpman (1994b) have shown that it emerges in a political system in which special interests design contributions in the above described-way, and two parties compete for seats in parliament. ${ }^{19}$

So suppose again that the economy is the same as in section 2.1 , but that the policy maker's objective function is $C+a W$, where $C$ stands for campaign contributions that he amasses, $W$ represents aggregate welfare (or per capita welfare), and $a$ is a parameter that represents the marginal rate of substitution between welfare and contributions. The larger $a$, the more weight is placed on the well being of voters relative to contributions. ${ }^{20}$ Contributions depend on the policy choice and so does welfare, and the policy maker maximizes this political objective function.

driven-contributions approach. For some purposes the details of the influence-driven-contributions approach are not needed. For other purposes, however, they are essential.

${ }^{19}$ Each party seeks to maximize its expected number of seats. The probability of successfully promoting a policy depends on the number of seats in command. A party uses contributions from special interests to influence the voting pattern of uninformed or 'impressionable' voters. On the other hand, each informed voter casts her ballot on the basis of whichever party commits to a policy that she most prefers. Except that each voter may have preferences between the parties that are based on other considerations as well, such as their positions on non economic issues. This leads to probabilistic voting. In this framework a party can choose a policy that is desirable to the general public and thereby secure the support of informed voters. Instead it can tilt its policy position in favor of special interests in order to gain campaign contributions. In this event it loses the support of some of the informed voters, but it can use the contributions to gain support from the impressionable voters. This tradeoff between the support of the two groups of voters, and a party's objective to attain as many seats as possible in parliament, translate into a desire to maximize an objective function that is increasing in contributions and in the well being of the general public. This function is linear when the distribution of preferences over non economic issues is uniform. The parameters of the political objective function depend on the degree of dispersion of these preferences, on the non economic bias in the preferences of voters, the number of informed relative to uninformed voters in the population, and the effectiveness of campaign spending in attracting impressionable votes.

${ }^{20} \mathrm{As}$ explained in the previous footnote, in the Grossman and Helpman (1994b) model of electoral competition with special interests $a$ depends on a variety of the underlying parameters. 
Now consider the special interest groups. Suppose that in some subset of sectors, denoted by $\mathcal{L} \subset\{1,2, \ldots, n\}$, the owners of the sector-specific inputs form lobby groups. Let $\alpha_{i}$ represent (as before) the fraction of people who own the input in sector $i$. Also assume that each person owns at most one type of sector specific input. Then the aggregate well being of the individuals that belong to lobby $i$ is given by

$$
W_{i}(\tau)=l_{i}+\Pi_{i}\left(\tau_{i}\right)+\alpha_{i} \sum_{j=1}^{n}\left[\left(\tau_{j}-1\right) M_{j}\left(\tau_{j}\right)+S_{j}\left(\tau_{j}\right)\right]
$$

The first term on the right hand side represents their share in labor supply, the second term represents their income from the sector specific factor, and the last term represents their share in tariff rebates and in consumer surplus. ${ }^{21}$ The lobby's purpose is to maximize $W_{i}(\tau)-C_{i}$, where $C_{i} \geq 0$ is the contribution of lobby $i$. How should the lobby design its contributions?

Interest group $i$ takes the contribution functions $C_{j}(\tau)$ of all the other interest groups $j \neq i$ as given. Therefore it knows that if it does not lobby, the policy maker will attain the political welfare $G_{-i}=\max _{\tau}\left[\sum_{j \neq i} C_{j}(\tau)+a W(\tau)\right]$; i.e., the policy maker will choose a policy vector $\tau$ that maximizes its objective function, disregarding lobby $i$ 's preferences. ${ }^{22}$ It follows that if lobby $i$ wishes to affect the policy outcome, it needs to offer a contribution function that induces a policy change and provides the policy maker with at least $G_{-i}$. Namely, its contribution function has to satisfy

$$
C_{i}(\tau) \geq G_{-i}-\left[\sum_{j \neq i} C_{j}(\tau)+a W(\tau)\right]
$$

in order to implement $\tau$. This is the standard participation constraint in principalagent problems. Naturally, the interest group has no desire to give the policy maker

\footnotetext{
${ }^{21}$ Observe that unlike the example of the tariff formation function here we include contributions to welfare by all goods, not only the product of sector $i$. The reason is that we shall allow each interest group to lobby for trade taxes in all sectors (i.e., not only in the sector in which they have a stake in the sector specific factor). More on this point later.

${ }^{22}$ In order to simplify notation, I use $\sum_{j \neq i} C_{j}(\tau)$ as a short hand for the sum of contributions of all organized interest groups other than $i$.
} 
more than necessary in order to induce a policy change. Therefore it choose a contribution function that satisfies (9) with equality at the equilibrium point. The policy vector that maximizes the lobby's objective function $W_{i}(\tau)-C_{i}$ is then

$$
\tau^{i} \in \arg \max _{\tau} W_{i}(\tau)+\left[\sum_{j \neq i} C_{j}(\tau)+a W(\tau)\right] .
$$

The contribution function is designed to implement this policy vector, and there typically exist many contribution function that do it. Although lobby $i$ is indifferent as to which contribution function it uses in order to implement this policy vector, its choice may affect the decision problems of other lobbies. Therefore there often exist many combinations of contribution functions that implement the equilibrium policy vector as well as equilibria with different policy vectors (see Bernheim and Whinston (1986)). An equilibrium consists of feasible contribution functions $\left\{C_{j}^{\circ}(\cdot)\right\}_{j \in \mathcal{L}}$ and a policy vector $\tau^{o}$ such that: (a) $\tau^{o} \in \arg \max _{\tau} W_{i}(\tau)+\left[\sum_{j \neq i} C_{j}^{o}(\tau)+a W(\tau)\right]$ for all $i \in \mathcal{L}$; (b) $C_{j}^{o}(\cdot)$ implements $\tau^{o}$ for all $j \in \mathcal{L}$; and (c) $\sum_{j \in \mathcal{L}} C_{j}^{o}(\tau)+a W(\tau)=G_{-i}$ for all $i \in \mathcal{L}$.

To illustrate some of the relevant consideration, first suppose that there is only one organized interest group, say in sector $i$. Then the equilibrium policy vector maximizes $W_{i}(\tau)+a W(\tau)$. Using (4) and (8) this implies

$$
\tau_{j}-1=\frac{I_{j}-\alpha_{i}}{a+\alpha_{i}} \frac{X_{j}}{\left(-M_{j}^{\prime}\right)}
$$

where $I_{j}$ equals one for $j=i$ and zero otherwise. First note that only sector $i$, which is represented by an organized interest group, is protected. All other sectors are afforded negative protection. The reason is that the special interest group lobbies the policy maker for high prices in sector $i$, in which it is a net seller, and for low prices in all other sectors, in which it is a net buyer. The rate of protection in sector $i$ is higher the more concentrated is the ownership of the sector specific factor in that sector (because the less the lobby cares then about excess burden), the less weight the policy maker places on welfare relative to contributions (because the cheaper it 
is then to influence the policy maker with contributions), the larger the output level of the sector (because it raises the benefit of the influence motive), and the flatter the import demand function (because the lower is then the excess burden imposed on society, about which the policy maker cares). Observe that the effects of output and slope of the import demand function are the same as in the formulas that we derived from the direct democracy approach, the political support function approach, and the tariff formation function approach. In addition, the effect of the degree of concentration of ownership is similar to the tariff formation function approach, while the role of the marginal rate of substitution between welfare and contributions plays a similar role to the marginal rate of substitution between welfare and profits in the political support function approach. These analogies are not accidental. I have purposely constructed variants of the other approaches that enable us to draw these analogies with the influence-motive approach.

What happens when there is more than one organized interest group? Grossman and Helpman (1994a) have shown that if we restrict the contribution functions to be differentiable around the equilibrium vector $\tau^{o}$, then they have to be locally truthful; i.e., the gradient of $C_{i}^{o}(\cdot)$ has to equal the gradient of $W_{i}(\cdot)$ at $\tau^{o}$. This leads to the tariff formula

$$
\tau_{j}-1=\frac{I_{j}-\alpha_{\mathcal{L}}}{a+\alpha_{\mathcal{L}}} \frac{X_{j}}{\left(-M_{j}^{\prime}\right)},
$$

where $\alpha_{\mathcal{L}}=\sum_{j \in \mathcal{L}} \alpha_{j}$ stands for the fraction of people that own sector specific inputs. The difference between this formula and the previous one, which was derived for the case in which only one sector had an organized lobby, is the replacement of $\alpha_{i}$ with $\alpha_{\mathcal{L}}$. Therefore the interpretation remains very much the same. Importantly, now all sectors with organized pressure groups enjoy protection while sectors without lobbies are afforded negative protection. In the extreme case, when all sectors have organized pressure groups and every individual has a stake in some sector, there is free trade. Under these circumstances the lobbies battle for protection of their own interests and neutralize each other in the process. Despite the fact that none of them succeeds in 
securing higher prices for their clients, they typically spend resources in the process (as can be confirmed from the participation constraint). The role of the contributions in this case is to avoid being harmed by the other lobbies.

Formula (10) describes the resulting rates of protection when each lobby conditions its contributions on the entire tariff vector. In practice this may not be the case. A lobby of the textile industry is obviously very much concerned with the protection of textiles, but its interest in subsidizing imports of tea is much smaller. In the event it may choose to neglect the conditioning of its contributions on the policy towards tea, especially if it is costly to spread the lobbying effort across a large number of policy instruments. A complete model of the political process should include a specification of the lobbying technology, which will then determine relative costs of lobbying. We would then expect pressure groups to focus on their core activity and get involved in the design of other policies only when the direct or indirect benefits from doing so would be large or when the marginal cost of doing so would be small. To see what difference a focused lobbying effort can make, suppose that the lobby of sector $i$ conditions its contributions only on $\tau_{i}$, for $i \in \mathcal{L}$. In this event there will be free trade in each sector that does not have an organized interest group while in the sectors with pressure groups the rates of protection will be

$$
\tau_{j}-1=\frac{1-\alpha_{j}}{a+\alpha_{j}} \frac{X_{j}}{\left(-M_{j}^{\prime}\right)} \quad \text { for } j \in \mathcal{L} .
$$

We see that the effects of the sector's size and the slope of its import demand function are the same as in the other formulas. Compared to the case in which pressure groups lobby for all policies, however, there are two major differences. First, now unorganized sectors are not protected while in (10) they are accorded negative protection. Second, now the rate of protection of an organized sector depends on the fraction of voters who have a stake in the industry (i.e., $\alpha_{i}$ ) while in (10) it depends on the fraction of voters who belong to any lobby, not necessarily the lobby of the industry under consideration (i.e., $\alpha_{\mathcal{L}}$ ). The implication is that now the degree of concentration of the ownership in a sector has a direct effect on its rate of protection; sectors with higher 
concentration of ownership attain higher protection. This is a desirable feature, as it finds support in reality.

My discussion has focused on trade taxes. It should be clear, however, that the same tools of analysis can be applied to other policy instruments as well. ${ }^{23}$ There is a major question, however, concerning the choice of instruments of protection. Why use tariffs rather than output subsidies, for example, when the latter instrument is more desirable on efficiency grounds? Partial answers, based on political economy considerations, are provided by Rodrik (1986) and Grossman and Helpman (1994a). But as Rodrik (1995) argues forcefully, the choice of instrument is a central question that has received only limited attention. Since good answers to this question are not yet available, I shall proceed to the next topic.

\section{Double-Edged Diplomacy}

We have so far examined situations in which trade policies are pursued by a single country facing constant world prices. This simplification helped us to focus on the internal politics; i.e., the interaction between lobbies and policy makers. Much of trade policy is effected, however, by international constraints. As a result, even when a country sets its own trade policy agenda it has to consider the international repercussions. This is particularly so for large countries. But countries also negotiate trade rules, tariff reductions, voluntary export restraints, free trade areas, and other items. Therefore an analysis of the formation of trade policies is incomplete without paying attention to the international interactions.

In view of these remarks it is only appropriate to consider the formation of trade policies in a framework that emphasizes two levels of strategic interaction. On the one hand governments set trade policies facing each other in the international arena. On

\footnotetext{
${ }^{23}$ See, for example, Dixit (1995) for an application to commodity taxation. Similar methods can be used to deal with quotas and other forms of quantitative restrictions.
} 
the other hand each government has to deal with its internal political system. This type of two-level interaction produces a simultaneous dependence between the internal and the external politics. A government that, say, negotiates a free trade agreement, is aware in its dealings with the foreign government of the domestic consequences of such an agreement. At the same time, domestic pressure groups that wish to influence the policy outcome are aware of the negotiation process, and of the pros and cons of alternatives results. These dependencies are the source of the title of this section, which is taken from the title of a book by Evans, Jacobson and Putnam (1993). Their book describes a series of case studies, building on the conceptual framework that was developed by Putnam (1988) in order to study situations of this sort. In the rest of this section I describe three examples that build on two-level interactions: noncooperative tariff setting, negotiated tariffs, and negotiated free trade agreements.

\subsection{Trade Wars}

Grossman and Helpman (1995a) have extended the influence-driven contributions approach to a setting with two countries that set trade policies non-cooperatively. In each country the economy is structured as in section 2.1, pressure groups lobby the domestic policy maker in the manner described in section 2.5 , and the policy maker maximizes a political objective function that is linear in contributions and aggregate welfare. ${ }^{24}$ Both the lobbies and the policy maker take as given the policy vector of the other country. But they do take into account the fact that domestic policies affect the terms of trade. In particular, denoting the countries by $A$ and $B$ and the international price by $\pi_{i}$, the world market clearing condition for product $i$, $\sum_{K=A, B} M_{i}^{K}\left(\tau_{i}^{K} \pi_{i}\right)=0$, defines implicitly the international price as a function of the trade policies in the two countries. Using this relationship, it is possible to derive a set of contribution schedules and a domestic policy vector that are the political

\footnotetext{
${ }^{24}$ It is also possible to allow pressure groups to lobby foreign governments, as shown in Grossman and Helpman (1995a).
} 
response to the trade policy of the other country. A similar political response can be defined for the other country. An equilibrium consists of contribution schedules and a policy vector for each country, such that the contribution schedules and the policy vector of each country represent a political response to the trade policy of the other country. These equilibrium trade policies satisfy

$$
\tau_{j}^{K}-1=\frac{I_{j}^{K}-\alpha_{\mathcal{L}}^{K}}{a^{K}+\alpha_{\mathcal{L}}^{K}} \frac{X_{j}^{K}}{\left(-\pi_{j} M_{j}^{K \prime}\right)}+\frac{1}{e_{j}^{L}} \quad \text { for } K, L=A, B \text { and } L \neq K,
$$

where $e_{j}^{L}$ is the export supply elasticity of country $L$ in sector $j$ (this elasticity is negative if the country imports the product). This formula has two parts: a political power index that is identical to (10) and a second part that captures terms of trade considerations. The latter, which is well known from Johnson (1953/4) and the now standard optimal-tariff formula, states that a tariff should be higher the less elastic is the foreign export supply function.

The tax rate of country $K$ in sector $i$, as given by (11), depends on the trade policy in the other country (i.e., it depends on it through the international price $\pi_{j}$ ). This interdependence has some interesting implications. In particular, for constant elasticity import demand and output supply functions, it implies that a lower weight on welfare relative to contributions in the political objective function of the importing country leads it to take a more aggressive policy stance. As a result its terms of trade improve, its tariff is higher - and sufficiently so as to secure a higher domestic price for the protected industry - and the domestic price in the exporting country is lower. It follows that the same industry in the exporting country receives less protection, or that it is afforded more negative protection. This example demonstrates how a change in the political environment in one country affects the resulting degree of protection in each one of them. Evidently, this type of analysis helps to see how trade policies of one country depend on the political environment in the other. 


\subsection{Trade Talks}

In section 3.1 trade taxes were set non-cooperatively. As a result, policy makers inflicted deadweight loss not only on the residents of the two countries, but also on each other. To avoid some of this political damage they can set trade policies cooperatively, as governments often do.

When governments negotiate trade policies they are aware of the political repercussions at home, including those that are related to special interest groups. These repercussions affect their strategy. At the same time campaign contributions of special interest groups are designed differently when they expect the policy makers to negotiate than when they expect them to set policies non cooperatively. In anticipation of negotiation a lobby designs its contribution schedule so as to tilt the agreement in its favor. The best schedule depends on the institutional framework in which the negotiations take place. As shown in Grossman and Helpman (1995a), however, as long as the negotiating procedure allows policy makers to choose from the outcomes that are efficient from their own perspective, the resulting equilibrium policy vectors satisfy

$$
\tau_{j}^{A}-\tau_{j}^{B}=\frac{I_{j}^{A}-\alpha_{\mathcal{L}}^{A}}{a^{A}+\alpha_{\mathcal{L}}^{A}} \frac{X_{j}^{A}}{\left(-\pi_{j} M_{j}^{A \prime}\right)}-\frac{I_{j}^{B}-\alpha_{\mathcal{L}}^{B}}{a^{B}+\alpha_{\mathcal{L}}^{B}} \frac{X_{j}^{B}}{\left(-\pi_{j} M_{j}^{B \prime}\right)} .
$$

This formula determines only the relative values $\tau_{j}^{A} / \tau_{j}^{B}$, which are independent of the negotiation procedure. They ensure that the outcome is on the efficiency frontier of the governments. It is then possible to use the levels of these policy variables, or direct transfers between the governments (as in the Common Agricultural Policy in Europe), to select a particular distribution of gains on the efficient frontier. ${ }^{25}$ Which particular distribution the governments choose depends on the negotiation procedure, as well as on a variety of economic and political variables. ${ }^{26}$

Importantly, an industry is protected in country A but not in B if and only if the political power index of this industry is larger in A. Negotiations over trade taxes

\footnotetext{
${ }^{25}$ See also Mayer (1981) on this issue.

${ }^{26}$ See Grossman and Helpman (1995a) for an example.
} 
bring special interests of an industry from the two countries to take opposing sides of the issue; each one of them wants to be protected at the expense of the other. As a result they exert opposing pressures on the negotiating parties and the winner is the lobby with the larger political clout. Thus, for example, if the textile industry is organized in country $A$ but not in $B$, textiles will obtain positive protection in $A$ and negative protection in $B$, relative to free trade. Formula (12) also shows that the governments will agree on free trade in textiles (or the same internal price in both countries) if and only if the political power indexes of the textile lobbies are the same in both countries.

Finally, observe that contrary to (11), no export supply elasticities appear in (12). This stems from the fact that in a trade war each government is using trade taxes to also better its nation's terms of trade. When the governments negotiate, however, the use of terms of trade as a means of income transfer is politically inefficient. Therefore they do not use them in the cooperative design of trade taxes.

\subsection{Free Trade Agreements}

Another important example of negotiated trade policies is provided by free trade agreements (FTAs). Unlike negotiated trade taxes, however, FTAs involve discrete choices (although some continuity is available via the specified terms). The GATT article of agreement XXIV allows countries to form a free trade area in exception to the "most favored nation" clause if the agreement eliminates duties and restrictions on "substantially all trade" among the contracting parties. Grossman and Helpman (1995b) have studied the political economy of such agreements when interest groups that represent various industries express their concerns by means of campaign contributions. Each interest group can voice its support or opposition to an agreement by contributing money in case an FTA forms or in case the FTA is rejected.

First suppose that a country contemplates joining a free trade area with well specified terms that it cannot affect. Each sector is represented in the debate over 
the agreement, and the representatives of an industry seek to maximize the return to the sector specific input. The government seeks to maximize $C+a W$, as in section 2.5. The economic model is the same as in section 2.1. In these circumstances the policy maker has to choose one of two regimes: regime $F$; i.e., joining the free trade area, or regime $N$; i.e., not joining. Sector-specific income in regime $R=F, N$ equals $\Pi_{i R}$ in sector $i$ and welfare is given by $W_{R}$. Lobby $i$ offers a pair of contributions $\left(C_{i F}, C_{i N}\right)$, the first one representing an offer in case regime $F$ is adopted and the second one representing an offer in case regime $N$ is adopted. One of the offers equals zero.

The first question to ask is what types of political equilibria arise in these circumstances? Grossman and Helpman show that two types may arise. If the regime that provides the higher aggregate welfare level generates a large enough welfare gain relative to the alternative, then there exists a political equilibrium in which the welfare superior regime is chosen by the government and all lobbies contribute zero. The welfare gain is large enough for this purpose if the product of $a$ with the welfare gain exceeds the largest loss that a single sector experiences when the welfare superior regime is selected. ${ }^{27}$ Clearly, with no contributions the government selects the welfare superior regime. The point is, however, that under the specified circumstances no lobby stands to gain enough from inducing the government to choose the welfare inferior regime in order to make it worthwhile for the lobby to contribute the required minimum that induces the policy maker to switch regimes. Evidently, this equilibrium builds on a lack of coordination among the lobbying groups, and each one separately does not have a big enough stake to induce a switch of regimes on its own.

Minimal coordination by pressure groups, in the form of non binding prior communication about preferable outcomes, leads to an equilibrium that is coalition proof.

\footnotetext{
${ }^{27}$ Let $R$ be the welfare superior regime; i.e., $W_{R}>W_{K}, R \neq K$. Then there exists an equilibrium in which contributions are zero and the government chooses $R$ whenever $a\left(W_{R}-W_{K}\right) \geq$ $\max \left[0, \max _{i}\left(\Pi_{i K}-\Pi_{i R}\right)\right]$.
} 
In such equilibria the policy maker chooses the regime that provides the highest joint welfare to the organized interest groups and the government. ${ }^{28}$ Moreover, every equilibrium in which contributions by at least one lobby support the selected regime is of this nature. In these equilibria contributions by opposing interest groups make the government just indifferent between the alternative regimes. The implication is that a delicate balance prevails in these equilibria, in the sense that about equal political strength supports each side of the issue. ${ }^{29}$

These results can be used to examine what pairs of countries are likely candidates for free trade agreements. An agreement requires both countries to select regime $F$ in the political equilibrium. For this purpose enough support in favor of the agreement has to be amassed in each country.

Now, support for an agreement can come from one of two sources. Either $F$ provides higher welfare, in which case the government will be happy to sign an agreement in order to please its voters. Or potential exporters to the free trade area, who expect to sell at higher prices in the partner country, are willing to contribute enough money in order to open those markets. Sectors that expect to face fiercer import competition in the free trade area oppose the agreement.

If the initial rates of protection reflect a political balance of power of the type described in section 2.5, then each country needs enough potential exporters that support the FTA in order to overcome the opposing political pressures. This means that the imbalance of trade between the countries has to be small enough, because one country's exports into the free trade area are the other's imports. Unfortunately, potential exporters that support the agreement do so because they expect to be able to charge higher prices, and higher prices are bad for welfare. As a result free trade agreements are most viable in situations in which the two countries are most likely

\footnotetext{
${ }^{28}$ Regime $R$ is selected in this case if and only if $\sum_{j \in \mathcal{L}} \Pi_{j R}+a W_{R} \geq \sum_{j \in \mathcal{L}} \Pi_{j K}+a W_{K}$.

${ }^{29}$ The fact that NAFTA has barely passed during the vote in US Congress can be interpreted as a reflection of this sort of equilibrium.
} 
to suffer joint welfare losses. ${ }^{30}$

Both countries are more likely to endorse an FTA if some politically sensitive sectors can be excluded from the agreement and allowed to maintain the original rates of protection. If given a choice, each country prefers to exclude sectors for whom the free trade area produces the largest joint loss of welfare and lobby income per unit of the overall constraining factor, where the constraining factor represents the interpretation of the term "substantially all trade" in article XXIV. Examples of the constraining factor include the fraction of industries that can be excluded from the agreement or the fraction of trade that takes place in exempted products. All sectors can be ranked according to this criterion and the cutoff point then determined by the overall constraint. ${ }^{31}$

It is quite unlikely, however, that both countries will have the same ranking of sectors according to this criterion. Under these circumstances a conflict arises over the set of exemptions and the countries need to reach a compromise in order to enact an FTA. Grossman and Helpman show that if the two governments engage in Nash bargaining over the exemptions, then they agree to exclude a set of sectors that is ranked according to a weighted average of the criterion that each country would like

\footnotetext{
${ }^{30}$ In this statement welfare is measure by $W$, and it does not include the well being of the government.

${ }^{31}$ Suppose there exists a continuum of sectors and that the overall constraint is given by $\int_{i \in E} T_{i} d i \leq T$, where $E$ represents the set of exempt sectors, $T_{i}$ represents the contribution of sector $i$ to the overall constraint, and $T$ represents the overall constraint. If, for example, the overall constraint is on the number of sectors that can be granted an exemption, than $T_{i}=1$ for every sector and $T$ stands for the largest measure of sectors that are allowed to be excluded from the FTA under article XXIV. On the other hand, if the constraint is on the trade volume, than $T_{i}$ stands for the trade volume in sector $i$ and $T$ represents the maximum trade volume that can be excluded from the agreement. The ranking of industries builds on the index $g_{i}=\left(a \Delta W_{i}+\Delta \Pi_{i}\right) / T_{i}$, where $\Delta W_{i}$ represent the welfare gain in sector $i$ from the FTA and $\Delta \Pi_{i}$ represents lobby $i$ 's income gain from the FTA. Indexing the sectors in an increasing order of $g_{i}$, the government wants to exclude the sectors for which $g_{i}$ is negative, as well as sectors with positive values of $g_{i}$ up to the constraint permitted by $\int_{i \in E} T_{i} d i \leq T$.
} 
to use on its own. ${ }^{32}$ The weights reflect the relative bargaining powers of the two governments. And a cutoff point is determined by the overall constraint imposed by the term "substantially all trade".

These examples show the power of an approach that emphasizes two-way interactions between internal politics and international economic relations. They also show that - complications generated by such interactions notwithstanding - this approach yields interesting insights about important policy issues. Further enrichment of this framework is needed, however, in order to address problems of institutional design that are at the heart of the current debate about rules concerning trade, direct foreign investment. and intellectual property rights.

\footnotetext{
${ }^{32}$ Namely, sectors are ranked according to $\omega^{A} g_{i}^{A}+\omega^{B} g_{i}^{B}$, were $\omega^{K}$ is the weight of country $K$.
} The overall constraint remains the same as in the previous footnote. 


\section{References}

[1] Bernheim, Douglas B. and Michael D. Whinston, 1986. "Menu auctions, resource allocation, and economic influence." Quarterly Journal of Economics 101: 1-31.

[2] Coughlin. Peter J., 1992. Probabilistic Voting Theory. Cambridge: Cambridge University Press.

[3] Dixit, Avinash, 1995. "Special-interest lobbying and endogenous commodity taxation." mimeo, Princeton University.

[4] Evans, Peter, Harold Jacobson, and Robert Putnam (eds.) , 1993. Double-Edge Diplomacy. Berkeley: University of California Press.

[5] Feenstra, Robert C. and Jagdish N. Bhagwati, 1982. "Tariff seeking and the efficient tariff." In Bhagwati, Jagdish N. (ed.) Import Competition and Response. Chicago: University of Chicago Press.

[6] Findlay, Ronald and Stanislaw Wellisz, 1982. "Endogenous tariffs, the political economy of trade restrictions, and welfare." In Bhagwati, Jagdish N. (ed.) Import Competition and Response. Chicago: University of Chicago Press.

[7] Flam, Harry, 1992. "Product markets and 1992: Full integration, large gains"? Journal of Economic Perspectives 6: 7-30,

[8] Garber, Peter M. (ed.), 1993. The Mexico-U.S. Free Trade Agreement. Cambridge: The MIT Press.

[9] Grossman, Gene M. and Elhanan Helpman, 1994a. "Protection for sale." American Economic Review 84: 833-850. 
[10] Grossman, Gene M. and Elhanan Helpman, 1994b. "Electoral competition and special interest politics." The Foerder Institute for Economic Research, Working Paper No. 19-94.

[11] Grossman, Gene M. and Elhanan Helpman, 1995a. "Trade wars and trade talks." Journal of Political Economy 103:

[12] Grossman, Gene M. and Elhanan Helpman, 1995b. "The politics of free trade areas." American Economic Review 85:

[13] Hillman, Arye L., 1982. "Declining industries and political-support protectionist motives." American Economic Review 72: 1180-1187.

[14] Hillman, Arye L., 1989. The Political Economy of Protection. London: Harwood.

[15] Hillman, Arye L. and Heinrich Ursprung, 1988. "Domestic politics, foreign interests, and international trade policy." American Economic Review 78: 729-745.

[16] Johnson, Harry G., 1953/54. "Optimal tariffs and retaliation." Review of Economic Studies 21: 142-153.

[17] Jones, Ronald W., 1971. "A three factor model in theory, trade and history." In Bhagwati, Jagdish N. et al. (eds.) Trade, Growth and the Balance of Payments: Essays in Honor of C. B. Kindleberger. Amsterdam: North-Holland.

[18] Long, Ngo Van and Neil Vousden, 1991. "Protectionist responses and declining industries." Journal of International Economics 30: 87-103.

[19] Magee, Stephen P., William A. Brock, and Leslie Young, 1989. Black Hole Tariffs and Endogenous Policy Formation. Cambridge: The MIT Press.

[20] Magelby, David B. and Candice J. Nelson, 1990. The Money Chase: Congressional Campaign Finance Reform. Washington DC: The Brookings Institution. 
[21] Mayer, Wolfgang, 1981. "Theoretical considerations on negotiated tariff adjustments." Oxford Economic Papers 33: 135-153.

[22] Mayer, Wolfgang, 1984. "Endogenous tariff formation." American Economic Review 74: 970-985.

[23] Mayer, Wolfgang and Jun Li, 1994. "Interest groups, electoral competition, and probabilistic voting for trade policies." Economics and Politics 6: 59-77.

[24] Olsen, Mancur, 1965. The Logic of Collective Action. Cambridge: Harvard University Press.

[25] Peltzman, Sam, 1976. "Toward a more general theory of regulation." Journal of Law and Economics 19: 211-240.

[26] Putnam, Robert, 1988. "Diplomacy and domestic politics: The logic of two-level games". International Organization 42: 427-460.

[27] Rodrik, Dani, 1986. "Tariffs, subsidies, and welfare with endogenous policy." Journal of International Economics 21: 285-296.

[28] Rodrik, Dani, 1995. "Political economy of trade policy." In Grossman, Gene M. and Kenneth Rogoff (eds.) Handbook of International Economics Vol. III. Amsterdam: North Holland.

[29] Shepsle, Kenneth A., 1990. Models of Multiparty Electoral Competition. London: Harwood.

[30] Stigler, George, 1971. "The theory of economic regulation." Bell Journal of Economics 2: 3-21. 